\title{
ANÁLISIS ARQUEOLÓGICO DE LOS PARAMENTOS DEL FARO ROMANO LLAMADO TORRE DE HÉRCULES. (LA CORUÑA-ESPAÑA)
}

\author{
(ARCHAEOLOGICAL ANALYSIS OF THE WALLS OF THE ROMAN LIGHTHOUSE CALLED THE \\ HERCULES TOWER. LA CORUÑA-SPAIN)
}

Pablo Latorre González-Moro, Arquitecto.

Estudio de Arquitectura Latorre y Cámara-Madrid

ESPAÑA

L. Caballero Zoreda, Dr. Arqueólogo

Centro de Estudios Históricos. CSIC- Madrid

Fecha de recepción: $13-$ II-95

ESPAÑA

$105-17$

\section{RESUMEN}

Con motivo de la realización de las obras de restauración de este importante monumento -el único faro en uso de época romana- se decidió efectuar el análisis arqueológico de sus muros, con el fin de conocer mejor su técnica constructiva y concretar lo más exactamente posible la fecha de cada uno de sus elementos constructivos. De este modo se tendria un conocimiento histórico preciso de cada elemento a la hora de intervenir sobre él. Además se podría correlacionar en un futuro la secuencia histórica del edificio con la conseguida en la obligada excavación que se iniciaba en su alrededor. La importancia excepcional de este faro merecia un análisis arqueológico lo más meticuloso y preciso posible.

\section{SUMMARY}

On the occasion of the restoration of this important monument - the only lighthouse in use from the Roman times - an archaeological analysis of its walls was carried out in order to know better its construction technique and determine, as accurately as possible, the original date of each of its construction elements. It was thus possible to obtain a precise historical knowledge of each element when the restoration was about to begin. This also allowed a future correlating of the historical sequence of the building with that achieved in the obligatory excavation that was initiated in its surroundings. The exceptional importance of this lighthouse was worth the most meticulous and precise archaeological analysis possible.
El análisis de paramentos se hizo utilizando el método Harris estratigráfico aplicado al estudio de la arquitectura histórica. Para economizar al máximo el esfuerzo, pero perdiendo el mínimo de información, se decidió restringir el análisis al núcleo residual del faro romano, que está formado por cuatro habitaciones abovedadas, que crean una plantacuadrada repetida en tres pisos. Se renunció, por tanto, al análisis de la fachada y de la linterna actuales, obras en lo fundamental neoclásicas con reformas posteriores y perfectamente documentadas. Aún en el núcleo romano, de los 16 paramentos posibles se eligieron los ocho interiores de fachada, en los que se reflejan todas las intervenciones históricas que ha tenido el faro-incluso la neoclásica cuyo contacto se observa en los huecos de las ventanas-, considerándose repetición de ellas las que se manifiestan en los muros que separan las habitaciones.
Para el análisis se aprovecharon los andamios colocados en el interior de todo el faro, alternándolo con las labores de limpiezay restauración. Primero se dibujaron manualmente los muros elegidos -ante la imposibilidad de hacerlo por fotogrametría-, efectuando luego la lectura parejas de arqueólogo y arquitecto que se hacían cargo de cada zona, equivalente a los dos paramentos de cada habitación.

Nada más iniciar el proceso de análisis se descubrieron series de elementos constructivos romanos repetidos, que obligaban a multiplicar el número de fichas analíticas. La solución consistió en numerar con el mismo número estos elementos dentro de cada zona, después de asegurarse que tenían la misma morfología y se debían a la misma génesis constructiva. Básicamente se trataba de interfaces pertenecientes aetapas de obra por tongadas y los mechinales 

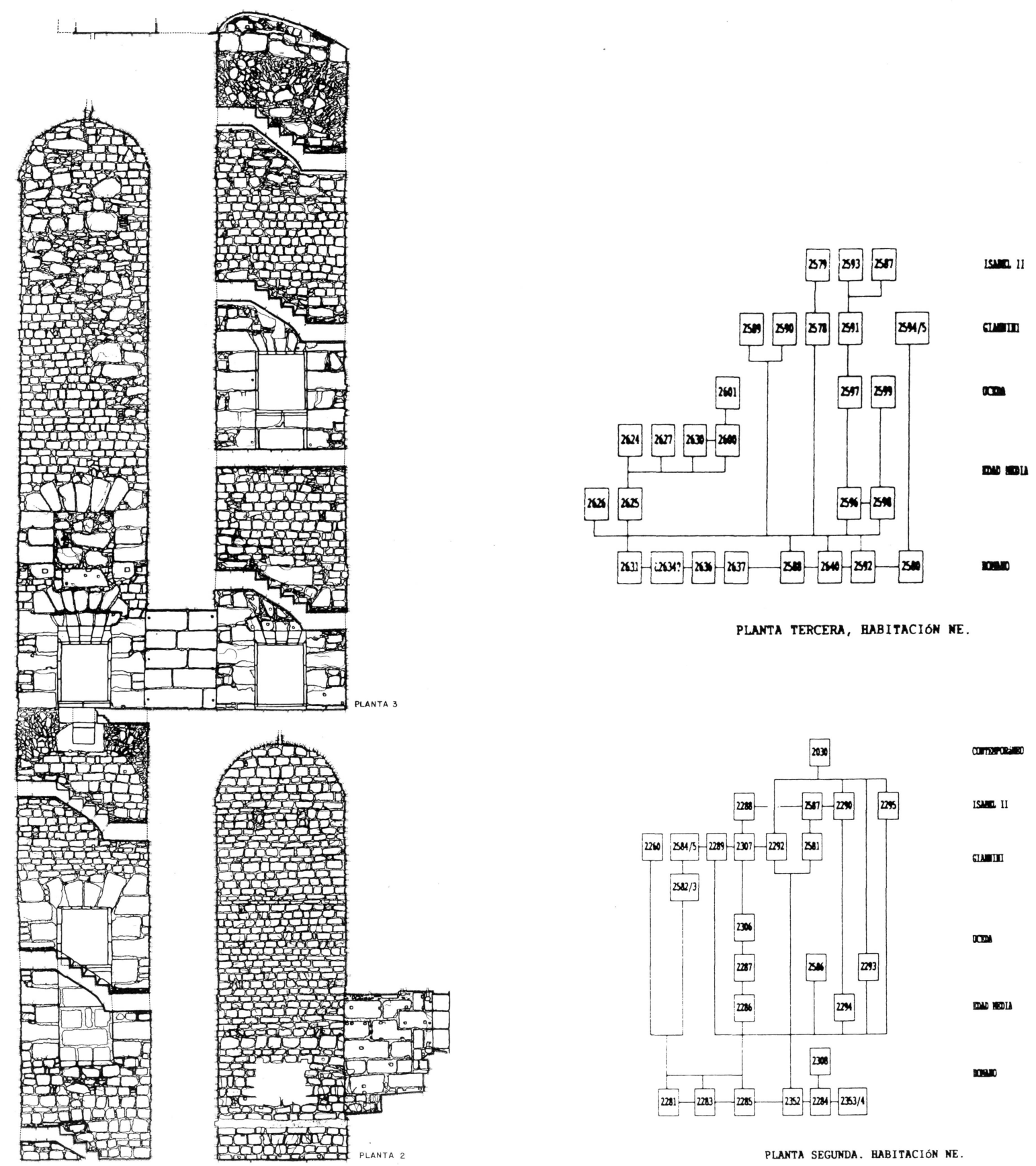

PLANTA TERCERA, BABITACIÓN NE.
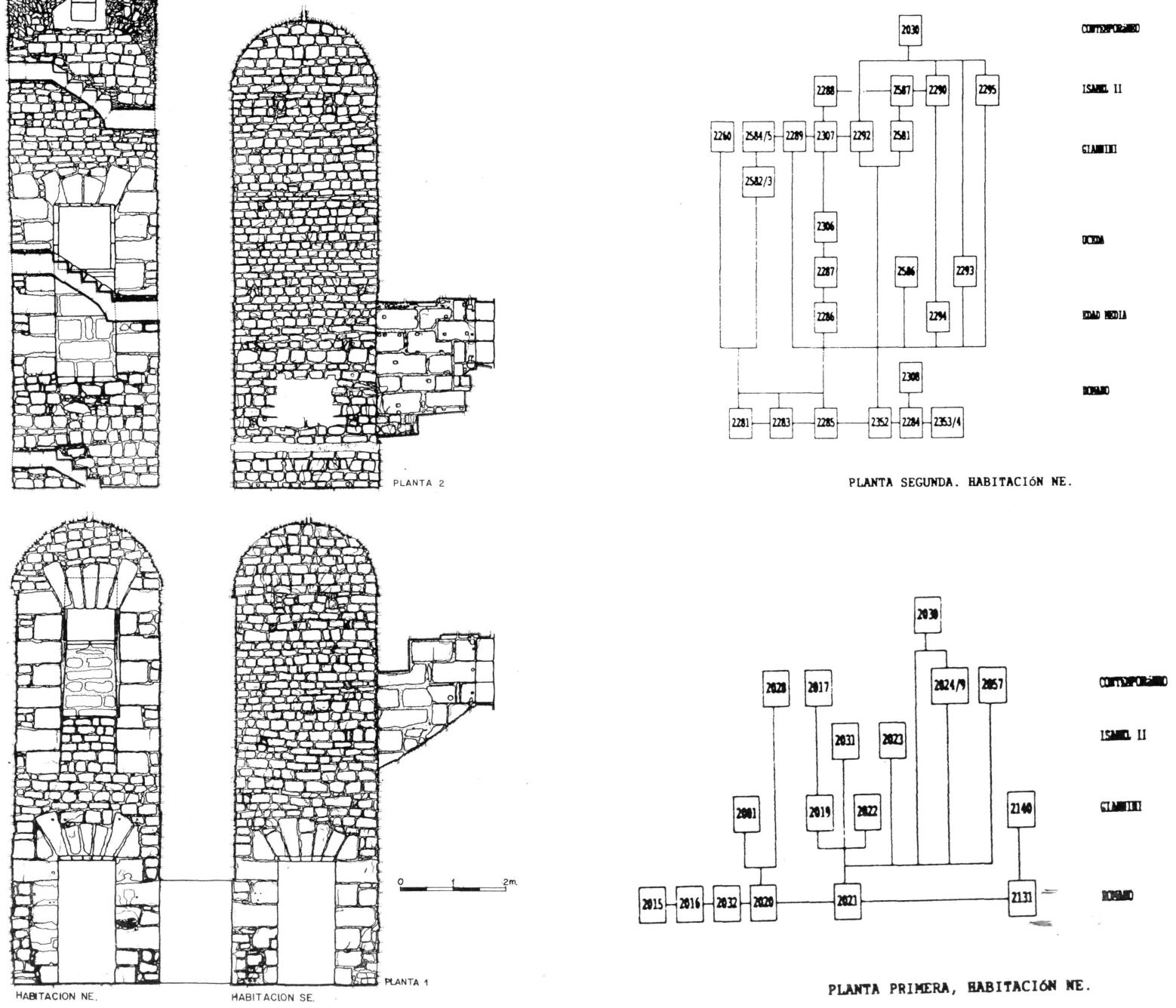

(c) Consejo Superior de Investigaciones Científicas Licencia Creative Commons 3.0 España (by-nc) 

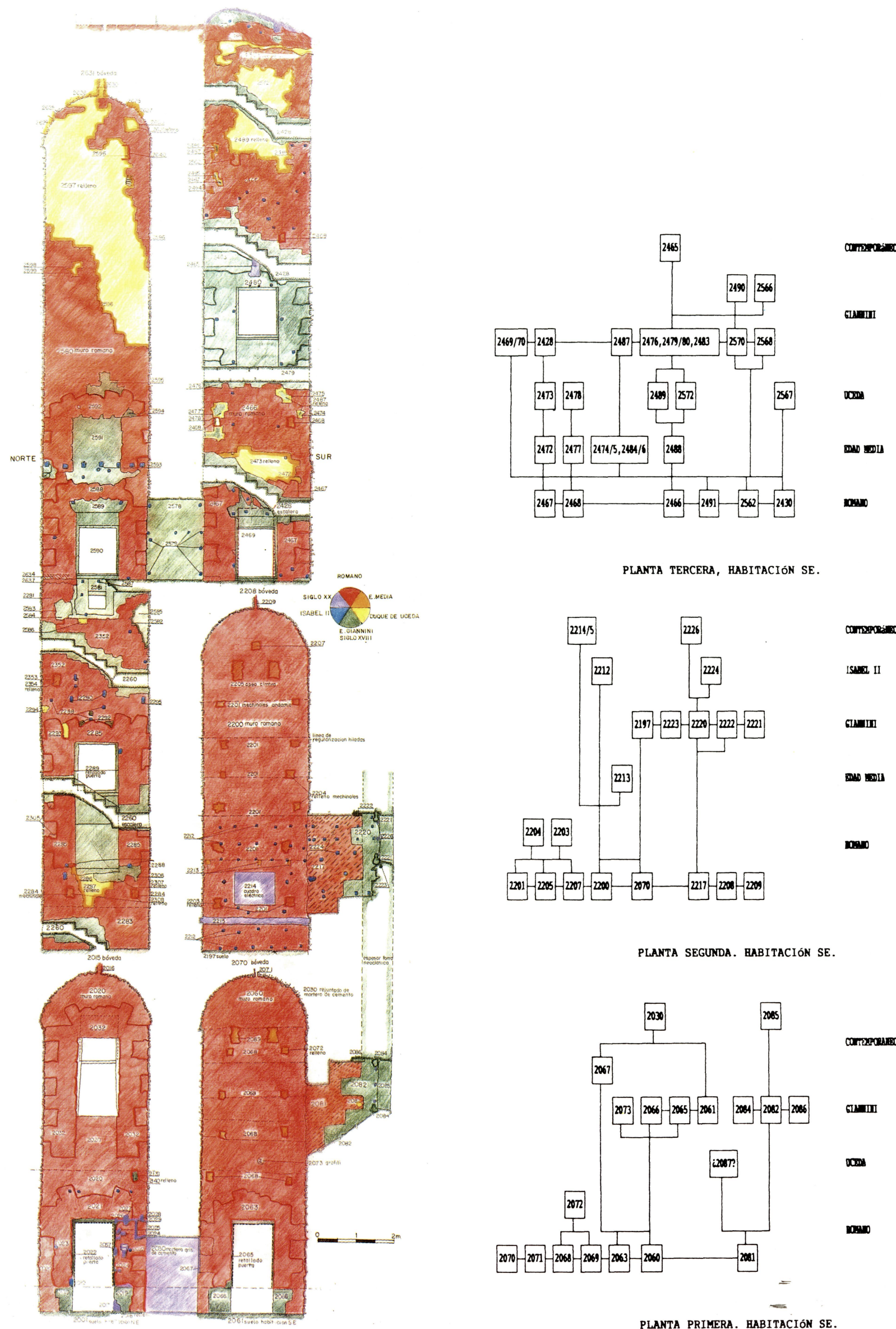

PLANTA TERCERA, HABITACIÓN SE.

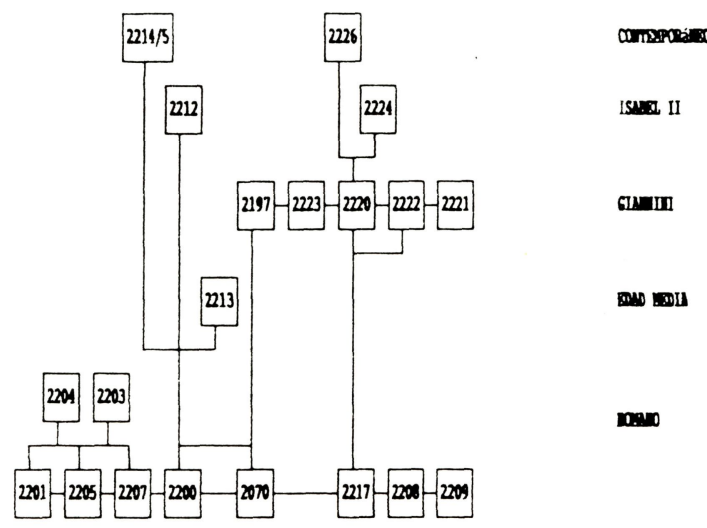

PLANTA SEgunda. BABITACIÓN SE.

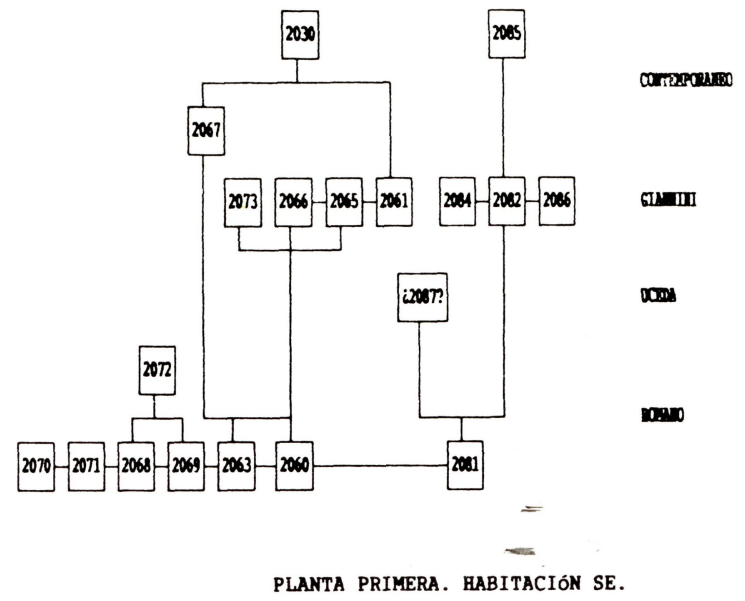


que sostuvieron los andamios. Las reducciones de los diagramas se efectuaron por zonas o habitaciones, sin que se realizara la correlación a estructuras dado que en la práctica sólo existían dos, las habitaciones romanas y la fachada neoclásica, perteneciendo los demás elementos a destrucciones o actividades restauradoras parciales. Los diagramas tienden a adoptar una forma extendida en horizontal, que corresponde a la descripción sincrónica horizontal-de los elementos y a la escasa diacronía -vertical -del edificio, ya que durante siglos -desde la desaparición de la rampa romana hasta las restauraciones modernas- fue imposible el acceso a su interior. La propia sencillez de su lectura la convierten en un modelo, por lo que hemos decidido traerla a estas páginas eligiendo una de sus secciones más expresivas, la oriental, comparando la planimetría que sirvió de base, con la conclusiva donde se han coloreado las fases históricas y con los diagramas correspondientes a cada zona.

Gracias al análisis se puede explicar con todo detalle la técnica romana de su construcción. Sería posible calcular el tiempo que se tardó en construirlo contando las etapas de obra, así como restituir la forma de los andamios, elevados con la propia obra. Se descubrió también cómo se construyeron las bóvedas, realizadas en opus caementicium vertido sobre cimbras sujetas por dos vigas apoyadas en mechinales con holgurasuficiente para permitir recuperarlas una vez fraguadas. Cadasuelo tenía en su centro geométrico un hueco que atravesaba las bóvedas que suponemos pudo estar en relación con el trazado a plomada de la obra.

En la secuencia final se distinguen especialmente las siguientes etapas:

-Romana.

-Altomedieval o anterior. La ruina de la fachada y la rampa de acceso.

-1684. La obra de la escalera de madera ordenada por el duque de Uceda y efectuada por Amaro Antúnez, que obligó a atravesar algunas bóvedas romanas.

-1788-1790. La restauración neoclásica de Giannini, con la construcción de la actual escalera de piedra.

-1888. El empapelado de las paredes y los falsos techos colocados con motivo de la visita efectuada por la reina Isabel II, retirado en 1905.

-Las actuaciones contemporáneas, como la sustitución en 1909 de labalaustrada de madera de la escalera de Giannini por otra de piedra, olacolocación de servicios, especialmente de instalaciones eléctricas.

\section{Ficha Técnica}

\footnotetext{
Promoción y financiación. Ministerio de Obras Públicas y Transporte. Área de Señales Marítimas y Demarcación de Costas de Galicia.

Redacteres del proyecto de restauración. L. Cámara Muñoz y P. Latorre González-Moro, arquitectos.

Análisis arqueológico del edificio. Director: L. Caballero Zoreda. Técnicos: M. Alba Calzado, arqueólogo; L. Cámara Muñoz, arquitecto; M. FernándeZ

Mier, arqueóloga; P. Latorre González-Moro, arquitecto; $\mathrm{M}^{\mathrm{a}} \mathrm{A}$. Pedregal Montes, arqueóloga.

Documentación planimétrica del interior. M.A. Núñez Villanueva e I. Martín Gutiérrez.
} 